\title{
Transcription of promoter from the human APRIL gene regulated by Sp1 and NF-kB
}

\author{
J. XU, W. F. DING, K. K. SHAO, X. D. WANG, G. H. WANG, H. Q. LI, H. M. WANG* \\ Department of Clinical Laboratory Center, Affiliated Hospital of Nantong University, Nantong University, 20 Xi Si Road, Nantong 266001, \\ China \\ *Correspondence: wanghuimin61@yahoo.com.cn
}

Received November 1, 2011 / Accepted December 21, 2011

\begin{abstract}
A proliferation-inducing ligand (APRIL) which stimulates the cell proliferation is abundantly expressed in colorectal cancer (CRC) tumors. In this report, the promoter region of the APRIL gene was determined and the major transcription factor was investigated for the first time. Deletion analysis of 5'-flanking region of the human APRIL gene and transient transfection revealed that a 538 bp region (from -1539 to -1001) was essential for promoter activation of the APRIL gene. The data from electrophoretic mobility shift assays (EMSA) indicated that the 538 bp promoter region was responsive to the specificity protein 1 (Sp1) and nuclear factor kappa B (NF-kB). Overexpression of Sp1 or NF-kB increased the activity of the APRIL promoter. Mithramycin A (inhibitor of Sp1) and Bay11-7082 (inhibitor of NF-kB) exhibited an inhibitory activity to APRIL promoter. Our results will benefit to the APRIL gene regulation investigation and contribute to discover new drug target for the APRIL gene therapy of CRC.
\end{abstract}

Key words: APRIL, promoter, Luciferase reporter assay, Sp1, NF-kB

A proliferation-inducing ligand (APRIL, also known as TNSF13A, TALL-2, and TRDL-1) has been cloned and identificated nearly before two decades. It is a type II transmembrane protein with an intracellular $\mathrm{N}$ terminus and extracellular $\mathrm{C}$ terminus which belongs to the tumor necrosis factor (TNF) family [1]. APRIL has three receptors B-cell maturation antigen (BCMA, TNFRSF-17), transmembrane activator and cyclophilin ligand interactor (TACI, TNFRSF13B) and heparan sulfate proteoglycans (HSPG). Binding of APRIL to BCMA and TACI can activate the classical NF-kB pathway which plays an important role in the initiation and promotion of cancer $[2,3]$. The interaction of APRIL and HSPG can promote APRIL-induced tumor cell proliferation [4]. However, the mechanism of these three receptors which are directly responsible for signaling events is ambiguous.

The human APRIL gene is located in chromosome 17p13.1 which has six exons and can be transcribed as three alternatively spliced mRNAs $[5,6]$. The APRIL gene has been investigated and discovered to be highly expressed in colorectal adenocarcinoma SW480 cells, Burkitt's lymphoma Raji and melanoma G361 cell lines. Our previous study has also revealed that there existed an overexpression of the APRIL in SW480 cells [7]. In addition, we demonstrated that the transfection of siRNA-APRIL into nude mice model of SW 480 colon cancer cell line can obviously inhibit tumor growth in vivo [8]. All of these results demonstrated that the human APRIL plays a vital role in the development and progression of CRC. Thus, the molecular mechanism of the human APRIL in CRC is imperative to be elucidated.

The promoter of APRIL gene hasn't been described before. The reason is that the most previous studies about the human APRIL were focused on its role as a related factor of BAFF (B cell activating factor) in the past decades. And also because the reason that the active biology of BAFF has became a "hot topic" in the human APRIL research field. In order to thoroughly define the signaling pathway, the regulatory mechanisms of the APRIL gene must first be identified. In this work, we found that the 538 bp promoter region (-1539 to -1001) was essential for transcriptional activation of the APRIL gene in human colorectal carcinoma cells. We also demonstrated that the transcription factors $\mathrm{Sp} 1$ and NF-kB play the key role in promoting the transcription of the human APRIL gene. The results will provide an indispensable basis for the general mechanisms of human APRIL gene study. 


\section{Materials and methods}

Cell culture. Human CRC cell lines SW480 and HT29 (Academy of life science, China) were cultured in Dulbecco's modified Eagle's medium (DMEM) supplemented with 10\% fetal bovine serum (GIBCO), 100 mg $/ \mathrm{ml}$ streptomycin, and 100 $\mathrm{U} / \mathrm{ml}$ penicillin. Cells were incubated at $37^{\circ} \mathrm{C}$ in the humidified incubator containing 5\% CO2.

Prediction of promoter region and transcription factor binding sites. The APRIL promoter region was identified with the Promoter 2.0 Prediction Server (http://www.cbs.dtu.dk/ services/Promoter/) and Promoter Scan program (http://wwwbimas.cit.nih.gov/molbio/proscan/) [9]. The CpG islands were found by using traditional $\mathrm{CpG}$ island identification method [10]. The potential transcription factor binding sites in the promoter region were predicted by TF search program (http:// molsun1.cbrc.aist.go.jp/research/db/TFSEARCH.html).

Cloning of the 5'flanking region of human APRIL gene. Human genomic DNA was purified from whole blood using Human Genomic DNA Extraction Kit (Qiagen, USA). A 2003 bp promoter fragment $(-1899$ to +103 , the nucleotides are numbered from the initiating ATG as +1 ) of the APRIL gene was amplified from human genomic DNA by PCR using the gene specific primers (Tab1). The primer was designed based on published sequences (GenBank ID: NM-003808). The PCR was performed in a $25 \mu \mathrm{L}$ reaction mixture. After an initial denaturation step at $94^{\circ} \mathrm{C}$ for $5 \mathrm{~min}$, the $\mathrm{PCR}$ reactions were carried out for 30 cycles at $94^{\circ} \mathrm{C}$ for $30 \mathrm{sec}, 55^{\circ} \mathrm{C}$ for $30 \mathrm{sec}$, and $72^{\circ} \mathrm{C}$ for $2 \mathrm{~min}$, with a final extension of $10 \mathrm{~min}$ at $72^{\circ} \mathrm{C}$. PCR products were gel-purified using a MinElute Gel Extraction Kit (Qiagen), digested with MluI and HindIII enzymes and then cloned into pGL3-basic (Promega, USA), a luciferase reporter plasmid. The recombinant vector was designated as APRIL-1899, verified by Sanger sequencing and restriction enzyme digestion.

Plasmid Constructs. Three deletion constructs (APRIL1539, APRIL-1001, and APRIL-304) were obtained by PCR using the APRIL-1899 fragment as template. The primer sequences used are shown in Table 1. Amplified fragments were double digested with MluI and HindIII and ligated into the equivalent sites of the pGL3-basic vector (Promega). Plasmids were purified using the QuickLyse Miniprep Kit (Qiagen) and verified by sequencing.

Transient transfections and luciferase assays. Plasmids were purified from bacterial cultures using the QIAGEN Plasmid Midi Kit (Qiagen). SW480 cells were seeded at a density of $2 \times 10^{5}$ cells per well in 24 -well dishes. After $24 \mathrm{~h}$ incubation, the cells grew to approximately $90 \%$ confluency and were transfected with the vector constructs using Lipofectamine 2000 transfection reagent (Invitrogen) in accordance with the manufacturer's protocol. The pGl4.74 vector (Promega) was used as an internal control to normalize the variations in transfection efficiency. The pGL3-Basic plasmid without promoter was transfected as the negative control $48 \mathrm{~h}$ after transfection, cells were washed with phosphate buffered saline and resuspended in Passive Lysis Buffer (Promega). The luciferase activity was assayed with the Dual Luciferase Reporter Assay System (Promega). All experiments were performed in triplicate.

Nuclear Extracts and Gel Shift Assays. Nuclear extracts were obtained from SW480 cells using NE-PER nuclear and cytoplasmic extraction reagents (Pierce Biotechnology, USA) according to the manufacturer's protocol. Protein concentration was determined by a BCA assay (Sigma). The reaction mixture for EMSA contained $1.5 \mu \mathrm{l}$ of $10 \mathrm{x}$ binding buffer (100 $\mathrm{mM}$ Tris-HCl pH 7.5, $500 \mathrm{mM} \mathrm{KCl}, 10 \mathrm{mM}$ DTT), $1 \mu$ of Poly (dI:dC) and $2 \mu \mathrm{g}$ nuclear proteins. After 20 min incubation at room temperature, $0.5 \mu \mathrm{l}$ of the biotinylated oligonucleotide was added and incubated for another $20 \mathrm{~min}$ at room temperature. Anlabeled probes were added to the reaction mixture 20 min prior to the addition of the labeled probe in competition experiments. The DNA-protein complexes were loaded onto the $6.5 \%$ polyacrylamide gels, electrophoresed at $155 \mathrm{~V}$ for $1.5 \mathrm{~h}$ at $4^{\circ} \mathrm{C}$ and then electroblotted to a nylon membrane at $390 \mathrm{~mA}$ for $40 \mathrm{~min}$. The transferred DNA was crosslinked to the membrane by UV light. The biotin-labeled DNA was detected with a LightShift Chemiluminescence EMSA kit (Pierce Biotechnology, USA).

Table 1. Primers used for amplification of different constructs of APRIL promoters

\begin{tabular}{|c|c|}
\hline Construct & Sequence \\
\hline \multirow[t]{2}{*}{ APRIL-1899 (-1899/+103) } & F: 5'ACGACGCGTCTTGCTGGTGGATGGTGTGCT3’ \\
\hline & R: 5'CCCAAGCTTAACTCAACCAGAGGGCAACT3’ \\
\hline \multirow[t]{2}{*}{ APRIL-1539 (-1539/+103) } & F: 5'GCGACGCGTCCATCCCACATAAATACAG3’ \\
\hline & R: 5'CCCAAGCTTAACTCAACCAGAGGGCAACT3’ \\
\hline \multirow[t]{2}{*}{ APRIL-1001 $(-1001 /+103)$} & F: 5'TCGACGCGTGAGCAGAGGTAGGAAGGCACACT3’ \\
\hline & R: 5'CCCAAGCTTAACTCAACCAGAGGGCAACT3’ \\
\hline \multirow[t]{2}{*}{ APRIL-304 (-304/+103) } & F: 5’ACTACGCGTTGTTCCTCCTGGGTGTCACT3' \\
\hline & R: 5'CCCAAGCTTAACTCAACCAGAGGGCAACT3’ \\
\hline \multirow[t]{2}{*}{ APRIL-538 (-1539/-1001) } & F: 5' GCGACGCGTCCATCCCACATAAATACAG3' \\
\hline & R: 5'CATAAGCTTCCACCTGGGGGCTGGAGGCA3’ \\
\hline
\end{tabular}

MluI restriction site (forward primer) and HindIII restriction site (reverse primer) were underlined. F: Forward, R: Reverse 


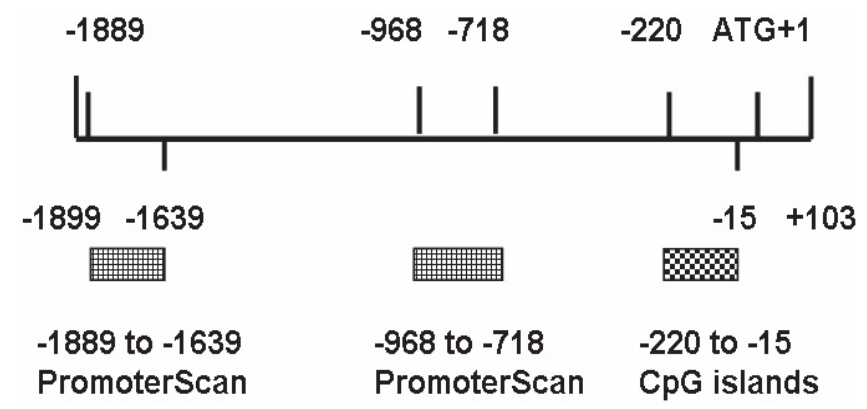

Figure 1. Analysis of 5'-flanking region of the human APRIL gene by bioinformatics. Schematic illustrating the location of putative APRIL promoter regions and $\mathrm{CpG}$ islands. The translation start site is position +1 and the rest of the sequence is numbered relative to it.

Oligonucleotides labeled with biotin and used in the EMSA analysis had the following sequences (the Sp1 and NF-kB sites are underlined):

wild type (Sp1): 5' TATTCGATCGGGGCGGGGCGAGC 3’ Mut (Sp1): 5' TGTTCAGGCTTGGGGGCGGGGACCTCCAT 3'

wild type (NF-kB) 5'GTAAGTTGAGGGGACTTTCCCA GGCCGT 3'

Mut (NF-kB): 5'CTTGGGGGCGGGGACCTCCATGCC TCCA 3'.

Corresponding unlabeled oligonucleotide probes were used for competition experiments.

Overexpression of NF-kB and Sp1. Sp1 expression vector pCMV-HA/Sp1 (a kind gift from Department of Immunology and Microbiology, Nantong University) and NF-kB p65 expression vector $\mathrm{pcDNA3} .1 / \mathrm{p} 65$ were cotransfected with pGL3-basic or APRIL-538 into SW480 cells, respectively. The empty vector pcDNA3.1 and pCMV-HA were used as negative control, respectively. $48 \mathrm{~h}$ later, cells were harvested for luciferase analysis.

Inhibition of NF-kB and Sp1. $24 \mathrm{~h}$ before transfection, SW480 cells were seeded in 6-well plates at a density of $2 \times 10^{5}$ cells per well. Different concentrations of inhibitor Bay11-7082 [11] (Sigma) and Mithramycin A (Sigma), a specific Sp1 inhibition [12] were directly added to the medium respectively 1 $\mathrm{h}$ before transient transfection of APRIL-538/pGL3-basisc into cells. Luciferase activities were measured after $24 \mathrm{~h}$.

Western blot analysis. SW480 cells were seeded in 6-well plates at a density of $2 \times 10^{5}$ cells. 24 hours later, SW480 cells were transiently transfected with NF-kB or Sp1 expression plasmids for overexpression studies and Bay11-7082 at $10 \mu \mathrm{M}$ or $100 \mu \mathrm{M}$ concentration, Mithramycin A at $10 \mathrm{nM}$ or $100 \mathrm{nM}$ was added directly to the media for inhibitor studies. 24 hours later, protein extraction and Western blot analysis were performed according to the methods previously described [8].

Statistical analysis. All data were analyzed using Stata software (version 11.0). Data are presented as mean \pm standard deviation. Student's t-test was used in statistical analysis.
A

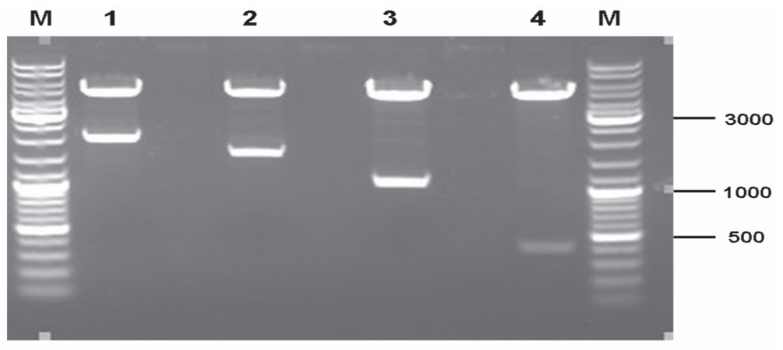

$\mathbf{B}$

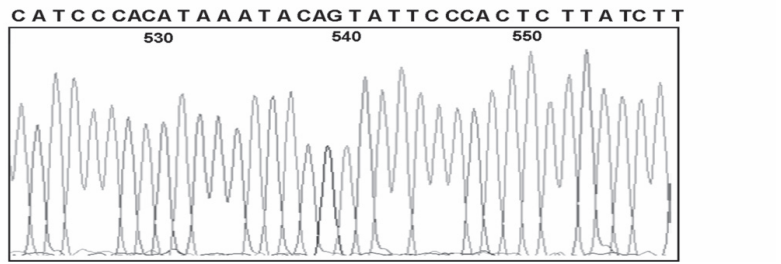

Figure 2. Verification of recombinant constructs. A - The restriction analysis of products by agarose gel electrophoresis. M: DNA marker (10 kb); Lane 1 to lane 4: recombinant plasmids (APRIL-1899, APRIL1539, APRIL-1001 and APRIL-304) digested with MluI and HindIII. B - The partial sequencing results of APRIL-1899.

\section{Results}

Structure analysis of the human APRIL promoter region. The $3.5 \mathrm{~kb}$ region of the 5 -flanking region of human APRIL gene was comprehensively analyzed by several programs, such as Promoter 2.0 Prediction Server, Promoter Scan and CpG Island Searcher. Promoter 2.0 predicted that the -999 (relative to the translation start site) position has a high score. Promoter Scan program identified the region of -1889 to -1639 and -968 to -718 as the potential promoter region of the human APRIL gene (Fig. 1). CpG Island Searcher revealed that the region from -220 to -15 was GC rich (Fig. 1). Then we added 10 bp upstream of -1889 and 119 bp downstream of -15 , so the final putative promoter region the human APRIL gene was -1899 to +103 .

Amplification of the APRIL promoter region and construction of luciferase reporter plasmids. We applied a series of unidirectional deletion method to analyze the $2003 \mathrm{bp}$ fragment in the 5'-flanking region of the human APRIL gene. The deletion fragments from -1899 to -304 were defined as 5 'ends ranging and +103 defined as 3'ends. Four truncation fragments of the human APRIL gene were obtained from genomic DNA by PCR. The size of each PCR product was 2003 bp, $1642 \mathrm{bp}, 1105 \mathrm{bp}$, and $407 \mathrm{bp}$. After that, the PCR products were digested with MluI and HinDIII enzymes and ligated into the promoterless luciferase reporter vector pGL3-Basic. The recombinant constructs were named as APRIL-1899, APRIL-1539, APRIL-1001, and APRIL-304 which separately verified by restriction enzyme digestion (Fig. 2A) and Sanger sequencing (Fig. 2B).

Functional characterization of the human APRIL promoter region. To identify the regions involved in the 


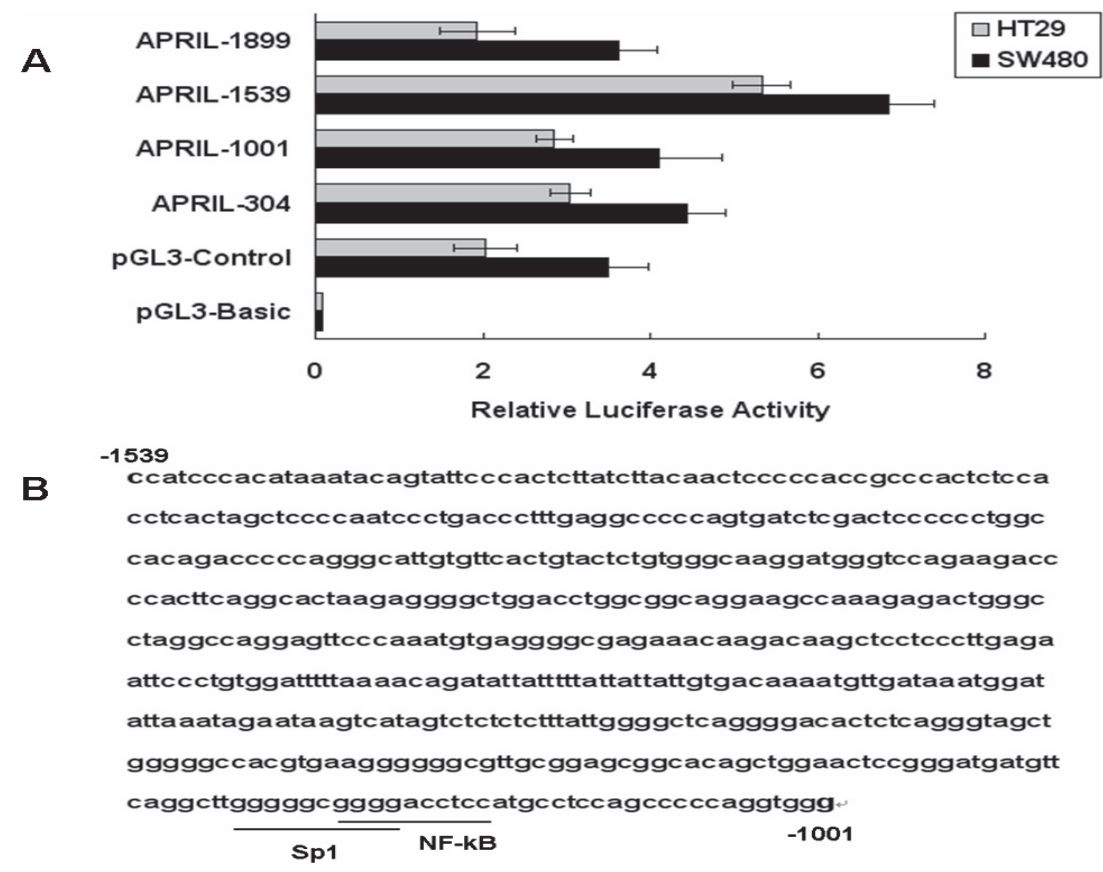

Figure 3. Function analysis of the 5'-flanking region of the human APRIL gene. A - Transient transfection analysis of APRIL promoter constructs. The diagram representation of the relative luciferase activity (firefly luciferase signal/renilla luciferase signal) of the four recombinant constructs compared with promoterless pGL3-Basic plasmid. Motifs of the APRIL promoter detected were APRIL-1889 (-1899 to +103), APRIL-1539 (-1539 to + 103), APRIL$1001(-1001$ to +103$)$ and APRIL-304 $(-304$ to +103$)$. All data represent the mean of three replicates. Error bars represent standard deviation. B - The nucleotide sequences of the -1539 to - 1001 region in the APRIL promoter. Underlines show the putative transcription factors binding sites.

regulating APRIL gene transcription, four recombinant constructions were transiently transfected into the human colon cancer cell lines SW480 and HT29. The plasmid pGl4.74 was used as an internal control for the normalization of transfection efficiency. Cell extracts were prepared and assayed for luciferase activity after 48h. As shown in Fig. 3A, the construction of APRIL-1539 revealed the highest luciferase activity among all the constructions in SW480 cells. The promoter activity of APRIL-1001 and APRIL-304 exhibited a lower level than APRIL-1539. The activity of APRIL-1899 was the lowest. The similar results were observed in HT29 cells. On the basis of above findings, we conjectured that the fragment between 1539 to - 1001 contain pivotal regulatory elements playing a key role on the APRIL promoter activity. So we used TFSEARCH program to investigate the possible transcription factor binding sites in this region and the corresponding transcription factors. The analysis revealed that two critical cis-acting elements for Sp1 was at the position -1029 to -1038 and for NF-kB was at the position -1023 to -1032 (Fig. 3B).

Sp1 and NF-kB binding to the APRIL promoter. To define whether Sp1 and NF-kB binding to the putative sites at the 538 bp promoter region of APRIL gene (APRIL-538), electrophoretic mobility shift assays (EMSA) was performed. The DNA-protein complexes were observed after incubation of Sp1 or NF-kB probe with nuclear extracts from SW 480 cells for $20 \mathrm{~min}$ at room temperature (Fig. 4. lanes 2, 3, 7, 8). The complexes were competed off by the addition of unlabeled $\mathrm{Sp} 1$ or NF-kB probes (Fig. 4. lanes 4, 5, 9, 10), suggest that the Sp1 and NF-kB protein specifically binds to APRIL-538.

Effects of transcription factor NF-kB and Sp1 on APRIL promoter activity and protein expression. In order to examine the effect of transcription factors of Sp1 and NF-kB on the regulation of APRIL, the promoter-luciferase reporter plasmid (APRIL-538) was cotransfected into SW480 cells with Sp1 or p65 expression vectors. The 538 represented the number of APRIL gene sequences which were located between -1539 and -1001 (the translation start site as +1 ). Recombinant plasmid APRIL-538 was obtained in accordance with the method described above. The primers used are shown in Tab. 1. Luciferase activity was measured $48 \mathrm{~h}$ after transfection. The luciferase activity of the APRIL promoter was highly increased by the overexpression of either NF-kB or Sp1 (Fig. 5A). The APRIL protein expression level in SW480 cells was increased significantly by NF-kB or Sp1 cotransfection, compared with that of the control cells transfected with empty plasmid (Fig. 5B). The results demonstrated that the transcription factor Sp1 and NF-kB can activate transcription of APRIL gene.

Effects of Mithramycin A and Bay11-7082 on APRIL promoter activity and protein expression. Inhibitors of $S p 1$ (Mithramycin A) and NF-kB (Bay11-7082) were preformed to further analyze the relation between transcription factors 


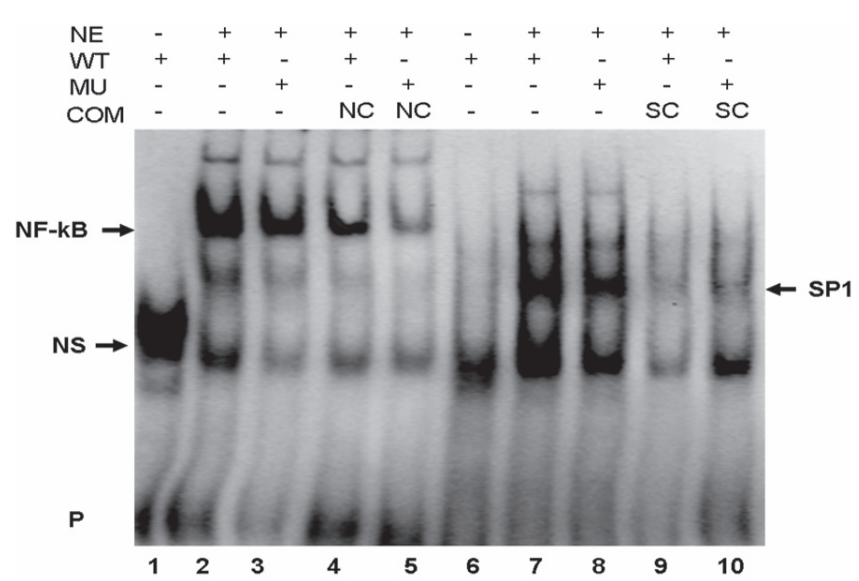

Figure 4. Interactions of Sp1 and NF-kB with their binding sites in the human APRIL promoter. EMSA displayed binding of nuclear proteins Sp1 and NF-kB to its binding sites of the APRIL promoter. Lanes 1 and 6, labeled probe only; lanes 2 and 7, nuclear extracts plus labeled wild-type probe; lanes 3 and 8 nuclear extracts plus labeled mutation probe; lanes 4 and 9, nuclear extracts plus labeled wild-type probe and cold unlabelled probe; lanes 5 and 10, nuclear extracts plus labeled mutation probe and cold unlabelled probe. NE: Nuclear extract; WT: Wild-type oligos; MT: Mutant oligos; NS: Non-Specific Binding; P: Free biotin labeled probe; COM: Unlabelled competitor.

and the APRIL promoter. The APRIL-538 luciferase activities were significantly reduced by adding Bay11-7082 and Mithramycin A (Fig. 6A). Similarly, Western blot analysis revealed a significant down-regulation of APRIL protein expression in SW480 cells incubated with Mithramycin A or Bay11-7082 compared to those in either untreated cells or cells treated with the DMSO vehicle only (Fig. 6B). These results demonstrated that Bay11-7082 and Mithramycin A decreased the Sp1 and NF-kB mediated APRIL and endogenous protein expression, respectively.

\section{Discussion}

Previous studies have shown that APRIL is abundantly expressed in colorectal adenocarcinoma SW480 cells as well as a promoting factor in various cancers such as solid tumors and various lymphomas $[1,13]$. Although the APRIL cDNA was already cloned in 2000 [6] and its role in tumors has been widely studied, little is known about the transcriptional activation and regulation of APRIL. In the present study, we have cloned and characterized the promoter region of the human APRIL gene.

Nucleotide sequence analysis of the $2003 \mathrm{bp}$ fragment $(-1899 /+103$, relative to the ATG start codon) from 5'flanking region of APRIL gene revealed that this region lacks a canonical TATA box, but exhibited a high GC content and CpG island density [14]. Transient transfection and luciferase analysis of each promoter-luciferase construction displayed either comparable or significantly higher activity than the

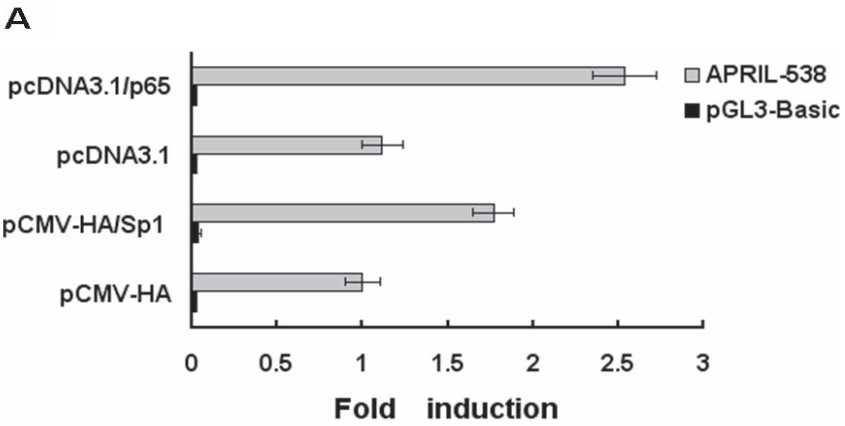

B

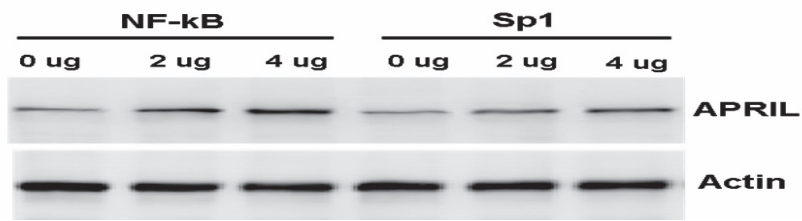

Figure 5. Effects of NF-kB and Sp1 on the APRIL promoter activity and protein expression. A - SW480 cells were cotransfected with the $2 \mathrm{ug}$ APRIL-538/ PGL3-basic and 2 ug of pcDNA3.1/p65, pCMV-HA/Sp1 and corresponding empty vectors. Results are displayed as fold induction compared with the empty vector transfection. The pGl4.74 vector was used as an internal control to normalize the efficiency. All data represent the mean of three replicates. Error bars represent standard deviation. B - SW480 cells were transfected with pcDNA3.1/p65, pCMV-HA/Sp1 and corresponding empty vectors. After $24 \mathrm{~h}$, protein extracts were prepared and analyzed by western blotting.

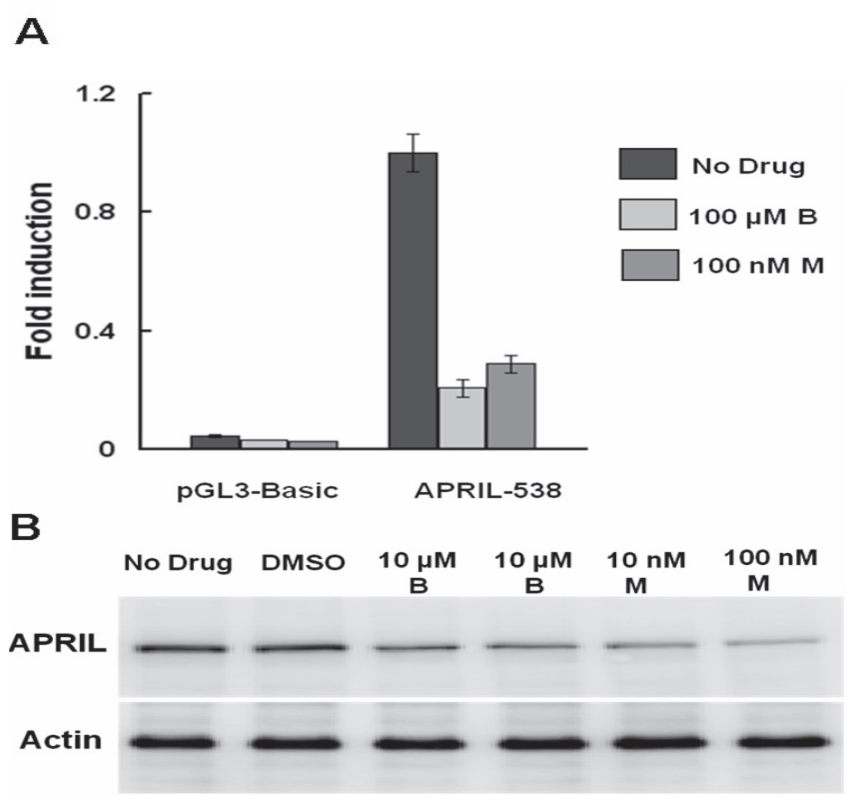

Figure 6. Effects of inhibitors on the APRIL promoter activity and protein expression. A - SW480 cells were transfected with 4ug APRIL-538 and incubated with the indicated concentrations of each drug for $24 \mathrm{~h}$. Results are displayed as fold induction compared with the no drug treatment. All data represent the mean of three replicates. Error bars represent standard deviation. B - SW480 cells were incubated with either DMSO, Mithramycin A or Bay1 1-7082 for 24h. Protein extracts were prepared and analyzed by western blotting. B: Bay1 1-7082; M: Mithramycin A 
pGL3-control plasmid containing the SV40 promoter. It is noteworthy that deletion from -1899 to -1539 significantly increased the activity of the APRIL promoter. However, further 538 bp deletion from - 1539 to -1001 reduced the activity of the APRIL promoter suggesting the 538 bp region might contain key regulatory elements which can highly activate transcription of APRIL gene. Thus TFSEARCH program was used to predict transcription factor binding sites and revealed that the 538 bp promoter region has two putative binding sites for Sp1 (-1029 to -1038$)$ and NF-kB (-1023 to -1032$)$. Their DNA-binding specificity was determined by EMSA.

Sp1 is a promoter-specific transcription factor [15]. It binds DNA through three $\mathrm{C}_{2} \mathrm{H}_{2}$-type zinc fingers located at the C-terminal domain [16]. The promoter region of APRIL is G/C rich and lacks TATA box which is in accordance with that $\mathrm{Sp} 1$ plays a critical role in activation of transcription of many TATA-less promoters by binding the GC-boxes [17]. Sp1 is abundantly expressed in mammalian cells and implicated in the growth and metastasis of many tumor types including human colon adenocarcinoma cells [18-22]. Our study also showed that Sp1 can improve the activity of APRIL promoter in colorectal cancer. APRIL may be yet another Sp1 regulated protein relevant to the metastatic biology of cancer.

Nuclear Factor-kB (NF-kB) is a ubiquitously encountered member of Rel family of transcription factors [23]. It is a p50/p65 heterodimer widely involved in inflammatory events and cancer development $[24,25]$. NF-kB can initiate or regulate gene transcription by binding the consensus sequence “GGGRNNYYCC” ( $\mathrm{R}=\mathrm{A} / \mathrm{G}, \mathrm{N}=$ any nucleotide, $\mathrm{Y}=\mathrm{T} / \mathrm{C})$ located in the promoter region. The NF-kB family is composed of NF-kB1 (p50/p105), NF-kB2 (p52/p100), p65 (RelA), RelB and c-Rel. The p65 subunit of NF-kB is indispensable for gene expression in response to TNF [26]. In our study, luciferase activity of APRIL promoter was significantly improved after co-transfection of p65 NF-kB expression vector (pcDNA3.1/ p65) into SW480 cells. And inhibition experiments further demonstrate that NF-kB serves an important role in regulating APRIL promoter activity. Previous study has shown that APRIL activates the canonical NF-KB pathway via both BCMA and TACI to stimulate proliferation and survival [27]. Thus, we can demonstrate that NF-kB is a major transcription factor involved in transcriptional regulation of human APRIL promoter.

Acknowledgements: This work was supported by grant XK200723 from Key Laboratory Subject of Jiangsu Province.

\section{References}

[1] HAHNE M, KATAOKA T, SCHROTER M, HOFMANN $\mathrm{K}$, IRMLER $\mathrm{M}$ et al. APRIL, a new ligand of the tumor necrosis factor family, stimulates tumor cell growth. J Exp Med 1998; 188: 1185-1190. http://dx.doi.org/10.1084/ jem.188.6.1185
[2] RENNERT P, SCHNEIDER P, CACHERO TG, THOMPSON J, TRABACH L et al. A soluble form of B cell maturation antigen, a receptor for the tumor necrosis factor family member APRIL, inhibits tumor cell growth. J Exp Med 2000; 192: 1677-1684. http://dx.doi.org/10.1084/je

[3] WU Y, BRESSETTE D, CARRELL JA, KAUFMAN T, FENG $\mathrm{P}$ et al. Tumor necrosis factor (TNF) receptor superfamily member TACI is a high affinity receptor for TNF family members APRIL and BLyS. J Biol Chem 2000; 275: 35478-35485. http://dx.doi.org/10.1074/jbc.M005224200

[4] HENDRIKS J, PLANELLES L, DE JONG-ODDING J, HARDENBERG G, PALS ST et al. Heparan sulfate proteglycans binding promotes APRIL-induced tumor cell proliferation. Cell Death Differ 2005; 12: 637-648. http://dx.doi.org/10.1038/ sj.cdd. 4401647

[5] MACKAY F, SCHNEIDER P, RENNERT P, BROWNING J. BAFF AND APRIL: a tutorial on B cell survival. Annu Rev Immunol 2003; 21: 231-264. http://dx.doi.org/10.1146/annurev.immunol.21.120601.141152

[6] KELLY K, MANOS E, JENSEN G, NADAULD L, JONES DA. APRIL/TRDL-1, a tumor necrosis factor-like ligand, stimulates cell death. Cancer Res 2000; 60: 1021-1027.

[7] DING W, WANG J, SUN B, JU S, YUAN H et al. APRIL knockdown suppresses migration and invasion of human colon carcinoma cells. Clin Biochem 2009; 42: 1694-1698. http://dx.doi.org/10.1016/j.clinbiochem.2009.06.019

[8] WANG F, DING W, WANG J, JING R, WANG X et al. Identification of microRNA-target interaction in APRIL-knockdown colorectal cancer cells. Cancer Gene Ther 2011; 18: 500-509. http://dx.doi.org/10.1038/cgt.2011.19

[9] HANNENHALLI S, LEVY S. Promoter prediction in the human genome. Bioinformatics 2001; 17: S90-S96. http://dx.doi. org/10.1093/bioinformatics/17.suppl 1.S90

[10] ZHAO Z, HAN L. CpG islands: algorithms and applications in methylation studies. Biochem Biophys Res Commun 2009; 382: 643-64 http://dx.doi.org/10.1016/j.bbrc.2009.03.076

[11] PIERCE JW, SCHOENLEBER R, JESMOK G, BEST J, MOORE SA et al. Novel inhibitors of cytokine-induced IkappaBalpha phosphorylation and endothelial cell adhesion molecule expression show anti-inflammatory effects in vivo. J Biol Chem 1997; 272: 21096-21103. http://dx.doi.org/10.1074/jbc.272.34.21096

[12] BLUME SW, SNYDER RC, RAY R, THOMAS S, KOLLER CA et al. Mithramycin inhibits SP1 binding and selectively inhibits transcriptional activity of the dihydrofolate reductase gene in vitro and in vivo. J Clin Invest 1991; 88: 1613-1621. http://dx.doi.org/10.1172/JCI115474

[13] ROOSNEK E, BURJANADZE M, DIETRICH PY, MATTHES T, PASSWEG J et al. Tumors that look for their springtime in APRIL. Crit Rev Oncol Hematol 2009; 72: 91-97. http://dx.doi. org/10.1016/j.critrevonc.2009.01.006

[14] BREATHNACH R, CHAMBON P. Organization and expression of eucaryotic split genes coding for proteins. Annu Rev Biochem 1981; 50: 349-383. http://dx.doi.org/10.1146/annurev.bi.50.070181.002025

[15] SUSKE G. The Sp-family of transcription factors. Gene 1999; 238: 291-300. http://dx.doi.org/10.1016/S0378$\underline{1119(99) 00357-1}$ 
[16] BRIGGS MR, KADONAGA JT, BELL SP, TJIAN R. Purification and biochemical characterization of the promoter-specific transcription factor, Sp1. Science 1986; 234: 47-52.

[17] WIERSTRA I. Sp1: emerging roles--beyond constitutive activation of TATA-less housekeeping genes. Biochem Biophys Res Commun 2008; 372: 1-13. http://dx.doi.org/10.1016/ j.bbrc.2008.03.074

[18] SAFE S, ABDELRAHIM M. Sp transcription factor family and its role in cancer. Eur J Cancer 2005; 41: 2438-2448. http://dx.doi.org/10.1016/j.ejca.2005.08.006

[19] GARTEL AL, GOUFMAN E, NAJMABADI F, TYNER AL. Sp1 and Sp3 activate p21 (WAF1/CIP1) gene transcription in the Caco-2 colon adenocarcinoma cell line. Oncogene 2000; 19: 5182-5188. http://dx.doi.org/10.1038/sj.onc.1203900

[20] ZHU GH, LENZI M, SCHWARTZ EL. The Sp1 transcription factor contributes to the tumor necrosis factor-induced expression of the angiogenic factor thymidine phosphorylase in human colon carcinoma cells. Oncogene 2002; 21: 8477-8485. http://dx.doi.org/10.1038/sj.onc.1206030

[21] TAKAMI Y, RUSSELL MB, GAO C, MI Z, GUO H et al. Sp1 regulates osteopontin expression in SW480 human colon adenocarcinoma cells. Surgery 2007; 142: 163-169. http://dx.doi. org/10.1016/j.surg.2007.02.015
[22] DONG W, SHEN R, WANG Q, GAO Y, QI X et al. Sp1 upregulates expression of TRF2 and TRF2 inhibition reduces tumorigenesis in human colorectal carcinoma cells. Cancer Biol Ther 2009; 8: 2166-2174. http://dx.doi.org/10.4161/ cbt.8.22.9880

[23] BALDWIN AS JR. The NF-kappa B and I kappa B proteins: new discoveries and insights. Annu Rev Immunol 1996; 14: 649683. http://dx.doi.org/10.1146/annurev.immunol.14.1.649

[24] CHEN F, CASTRANOVA V, SHI X, DEMERS LM. New insights into the role of nuclear factor-kappaB, a ubiquitous transcription factor in the initiation of diseases. Clin Chem 1999; 45: 7-17.

[25] KARIN M. Nuclear factor-kappaB in cancer development and progression. Nature 2006; 441: 431-436. http://dx.doi. org/10.1038/nature 04870

[26] VERMEULEN L, DE WILDE G, VAN DAMME P, VANDEN BERGHE W, HAEGEMAN G. Transcriptional activation of the NF-kappaB p65 subunit by mitogen- and stress-activated protein kinase-1 (MSK1). EMBO J 2003; 22: 1313-1324. http://dx.doi.org/10.1093/emboj/cdg139

[27] MARSTERS SA, YAN M, PITTI RM, HAAS PE, DIXIT VM et al. Interaction of the TNF homologues BLyS and APRIL with the TNF receptor homologues BCMA and TACI. Curr Biol 2000; 10: 785-788. http://dx.doi.org/10.1016/S0960-9822(00)00566-2 